\title{
Attendance Management System
}

\author{
K.J.H.D. Asiri ${ }^{1}$, K.S. Rishan ${ }^{1}$, U.A. Hewage ${ }^{1}$. , U.K.T. Prasadika ${ }^{1}$, \\ K.A. Dilini T. Kulawansa ${ }^{2}$ \\ ${ }^{1}$ Faculty of Information Technology, University of Moratuwa, Sri Lanka \\ ${ }^{2}$ Department of Computational Mathematics, Faculty of ,Information Technology, University of Moratuwa, Sri Lanka
}

\begin{abstract}
Attendance management plays an important role in the determination of the performance of an organization. This depicts the requirement of a methodology to monitor that. A research has been conducted to develop attendance management system with official visit tracking to analyze and manage attendance data using personal authentication methods. This solution consists of four modules for profile maintenance, leave management, report generation and attendance management which has been implemented by ASP.NET, Microsoft SQL, Bootstrap and Android. The solution has been tested with forty-four employees using a questionnaire which includes six aspects. The results show that the Attendance Management System has average overall rating of almost four, which illustrates achievement of a significant degree of acceptance level of all user requirements.
\end{abstract}

Keywords- Attendance Management; Leave Management Module; Profile Maintenance Module; Report Generation Module; Attendance Management Module.

\section{INTRODUCTION}

Software development is a field that show a great demand in the current job market even in Sri Lanka. With the development of the technology, this field has become much more competitive. Therefore, the management of almost all the companies may follow some techniques to enhance the efficiency of their employees. One of such problem that have been identified is about calculating the working hours of the employees of the company. Identification and verification are the two main objectives of use of biometric systems [11]. Nowadays the attendance recording system of employees in most of the companies has been done using more secure and reliable method biometric technologies with the use of biometrics such as fingerprint or faces [10], because personal authentication is more convenient than conventional methods such as ID or password. Together with that in-case if an employee go out for some official work there should be a proper method implemented to record his leave as working time. We are proposed to implement a system with graphical user interface (GUI) and also a mobile app to make this task easier for the client.
Calculating employees' working hours accurately are important for the company as well as for the employees. The working hours of an employee determines the contribution of ones for the company. This is also helpful for the identification of employee behavior patterns with respect to the absenteeism [6]. There can be enough of situations where an employee may need to attend to some task outside there office premises such as, meeting with clients, conferences, sessions and visit to client sites etc . In most of IT related companies, employees often participate for awareness sessions representing the company to be updated about latest technologies in the world. Other than that mostly client's meetings and conferences are very frequently occurring situations in the field of IT, because IT companies mostly deals with unique customer requirements. In these situations, the company can't monitor working hours through the current system which collects the attendance details of the employee [8]. If we are determining the contribution through monitoring the attendance the task engaged outside the premises also should be taken into consideration. But these data are not being used effectively for the decision-making process in most of the recently using systems. The company can use these data to identify problems and to find solutions that are related to the employees.

As an exception from the normal flow, if any employee leaves the office premises for any official task there should be a proper method to inform the management about his leave. Otherwise the leave will be noted as a private leave he has taken on his leave basis [9] .There is drastic difference between voluntary and involuntary absenteeism. People may take sick leave as they are not capable to do work due to bad health. Or sometimes people negotiated with the management to take vacation as sick leave [2]. However there are instances where an employee may have to take leave which are unexpected. So, in such a situation the employee has to email and inform about the leave. Although this is also an official method, we are trying to implement a system to make this task in a more userfriendly manner. Development of mobile app would greatly helpful for the enhancement of the user-friendliness 
of the system. This approach would result in the increase in the accuracy if the data, as the employees would much more deals with it in ease. Unscheduled absences and tardiness which result in unsatisfactory attendance may leads for disruption in work, which affects the productivity and create morale problems as the workloads are shifted to remaining employees [10]. In order to increase the productivity of the company these data thus collected should be well analyzed and that would be greatly helpful for the management purpose. Though data are collected through the fingerprint scanners, they are not used for any effective purpose.

The aim of our research is to develop a system for addressing attendance management using the data collected from fingerprint scanners. Section I gives the introduction to the research. Section II describes the reviews of others' work. It will discuss the key features of those systems. Section III is on the technologies we expect to use in the research. Section IV explains approach with respect to each and every group member in details. Section $\mathrm{V}$ provides details of the analysis and designing of the system we proposed. It will provide all the information about the structure of our system. Section VI discusses the method of implementation of the proposed system. Section VII will include the details of feedback analysis of the research. Section VIII is dedicated for the conclusion and further work which gives a summary about research. Most importantly, we discussed how our solution differ from similar work by others.

\section{RELATED WORK}

Some existing system related to our research title has been refereed thoroughly to identify the strength and the weakness of them. ADP Vista HCM system mainly focuses on the report generation on the data collected on attendance. this system is act as a self-service portal for employees which facilitates to view the attendance details and generate reports. Through this system employees can view the details of the approved and rejected attendance and leaves. And also requests regarding the leaves and attendance can be done using the same system. Other than that employee swipe details report, late in and early out of employee's reports are generated by the system. Attendance Management System for Industrial Worker Using Finger Print Scanner is about an industrial attendance management system based finger print scanner [7]. It was conducted in Khulna University of Engineering and Technology (KUET) in Bangladesh. The main objective of it is to update the top management of the company about the workers attendance information and to avoid giving fake attendance. This system is consisted with fingerprint scanner, display module and a computer. Here fingerprint scanner is used to obtain the attendance of the employees. It is connected to the server. After matching the fingerprint, the database is updated. Managers can view the attendance and the profile details of the employees by connecting with the server. As this system is connected with the server internet is a prerequisite. TimeOffmanager is such another system we referred. This is a web-based application with simple and user-friendly interface which manages the leave and has ability to generate reports. This system is developed to monitor the attendance and leave information of employees. Users of the system are categorized as administrators, managers and employees. By considering the users and departments daily, monthly and yearly reports are generated. Other than that administrators can view the employee details, reports, payroll and reject and accept the leaves through the system. University student attendance management system research was conducted by School of Computer Science for Business Management - Romanian-American University. This system is comprises with a timekeeping system which shows the check in and check out time of the students and teachers. Other than handling the attendance this system helps to generate reports. Web based attendance management system is another of such system, which was conducted in Gomal University by Dr.Muhammad Zubair Asghar [1]. This system is a dynamic and a flexible system. Reports are generated by analyzing and identifying the patterns of attendance. In addition to main features it posses the ability to schedule the task of employees also.

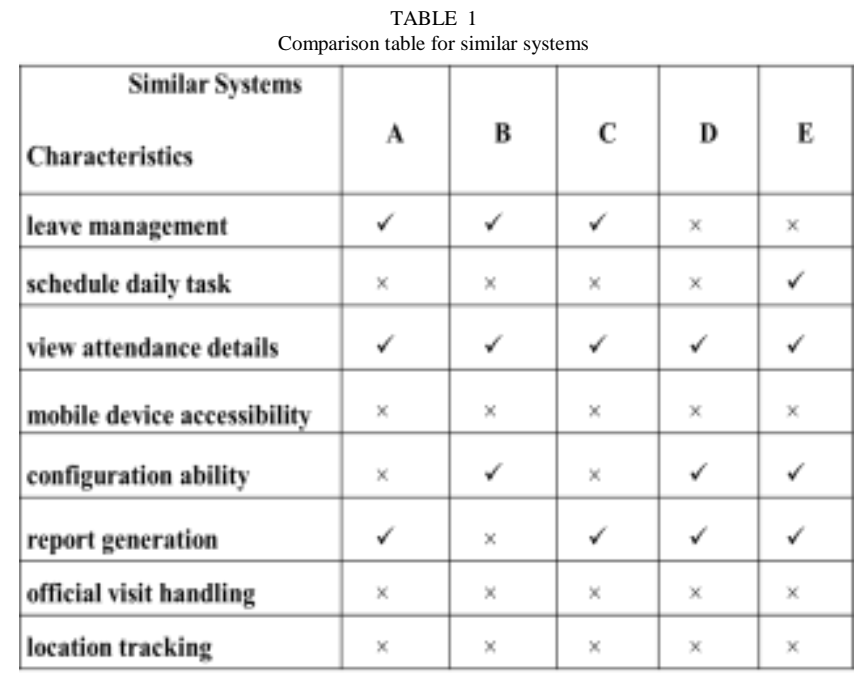




\section{TECHNOLOGY USED}

In this section, we discuss about technologies that we use in our system. Here we have selected four main areas, we figure out what are the requirements in our research, what the tasks that we have to accomplish, and the easiest methods to accomplish those tasks and what are the technologies that we use to make it success. Mainly in our system we have an android app, a database, a GUI, and a API. By thinking about the database we have selected Microsoft SQL as our query language[5], because using Microsoft SQL we can easily do modifications to our database and can give permissions to tables, procedures, views etc. To connect the database to the API we are going to use ASP.NET [4] as our back end as it is easy to handle the dynamic web pages and web applications using this. In addition, it is an open source framework and a cross platform to build internet connected applications. To connect GUI to the API we use Bootstrap as our front end as it is user friendly and easy implementation. In our system, we develop an android app, so we select Android as our other technology. In this chapter, we describe what are the special features in those technologies and how it fit to our research.

We use ASP.NET framework for the backend due to the reason that it is capable of handling web applications, dynamic websites and mobile application effectively. Due its popularity, the resources are available widely for ASP.NET making it easier for the developers. We decided to use Bootstrap in front end of our web application. It is user friendly and can handle user data that changes with the time. This is important for the web application of our system. We have decided to use Android to develop mobile application as it is the most widely used mobile operating system (OS). Android applications are developed in Java. Android is easy to develop due to the availability of resources like android studio, emulator, libraries etc. There is a database in our system. We decided to use Microsoft SQL to as technology related to the database. Using Microsoft SQL can be used to do easy modifications to database. Also, it helps to impose permissions on tables, procedures, views etc.

\section{OUR APPROACH}

Through this research we developed an attendance management system, which is comprises of many functionalities. Some of those functionalities can be listed as follows; requesting for a leave, add, update and delete an employee, track location of employee, view attendance and leave details, view a summary of weekly attendance details, being informed to apply for a leave, configure the limitations of leave, requesting duty leave for external visit, schedule daily ask, accept leave request and reject leave request. For the descriptive purpose, we have categorized them under four main modules. They are Leave Management, Profile Maintenance, Report Generation and Attendance Management [3]. Under these modules we are going to briefly discuss about the tasks assigned to these modules, functionalities in each module and who are responsible for those functionalities. Through this modularization we are hoping to enhance the simplicity of our system too. This system is having three actors. They are HR admin, manager and non-managerial employee. Each actor is assigned with separate tasks. So here these modules are developed in such a way that all the functionalities are well categorized and for better implementation. So in this chapter we are going to give a clear idea about what is happening in our system by categorizing the whole system into four modules.

\section{SOLUTION DESIGN}

The proposed system is consisted with a web application and a mobile application. In this system users are categorized as non-managerial employees, Managers and HR admin. Checking and check out time of employees are tracked using fingerprint scanners and that data is used in the proposed system. Mainly using that data working hours of the employees are calculated. This proposed system allow each and every employee to view his/her attendance for a desired time period. As well Managers and HR admin can view the attendance of all employees. By analyzing theses data reports are generated. Other than that employees are allowed to apply leaves using this system. Here leaves are categorized and employees can view their leave balance in each category. Also they can view the accepted rejected and pending leaves. These employee leave data also shown to the managers as reports using the same system. Also the system send notifications to the managers and the employees regarding leaves. If the working hours of an employee is less than his/her allocated time period then a notification is send to the relevant employee asking to apply a leave. In addition to that employees can allocate their daily tasks using the system. Other than that users can maintain their own profile. Update and delete the profiles are allowed. Also using this system managers can track the location of the employees when they left from the company for official purposes. The time period that employees spend for that purpose can be added to their working hours. 
Proc. of the Eighth Intl. Conf. on Advances in Computing, Electronics and Communication - ACEC 2019

Copyright ( $)$ Institute of Research Engineers and Doctors. All rights reserved. ISBN: 978-1-63248-165-8 DOI : 10.15224/978-1-63248-165-8-01

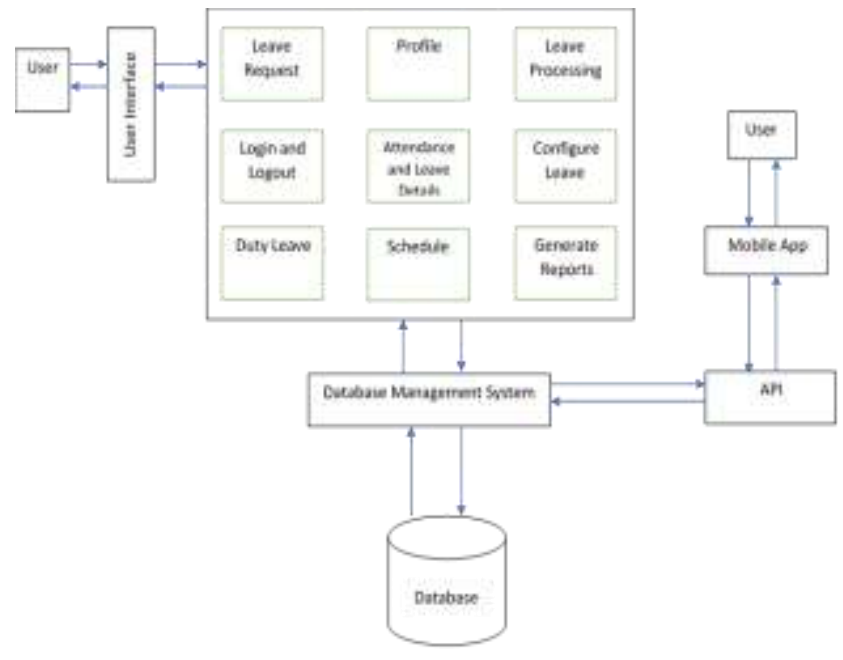

Fig. 1 Top level architecture of the proposed system

All these functions are carried out under four main modules; they are Leave Management Module, Profile Maintenance Module, Report Generation Module and Attendance Management Module.

\section{IMPLEMENTATION}

The main task of the research was to gathering the information and identifying the correct requirements of the end user. With the help requirements identified the system was designed according to that [12]. We decided that our system should have a web app and a mobile app. Our mobile app is developed using android. The implementation was done mainly based on four sections; front end, android app, database and the backend. The implementation of the database using Microsoft SQL was done prior to all the other takes. We started to develop the web and android interfaces also at the same time. The initiation of the development of the API was also conducted simultaneously.

Then we arrived to a conclusion about the features that contain in the web app and the mobile app separately. Because here we introduce the mobile app for easy accessibility of this application, so the mobile app consists with the most frequently used features.

Firstly the login part of the web app as well as the android app was developed. Then the registration part for the entry of new employees was done with the web app. This registration feature is only allowed in the web application. Once created each and every employee can view their own profile through both the apps. And also, the update and delete of the employee details was facilitated with the web app. The feature to apply for leaves by the employees was done through both the web app and the mobile app. By using both applications employees can view their leave details. Also notifications regarding to leaves are send in both mobile and web applications. Implementation was done on location tracking in both the apps. So that if it is a duty leave then the present location of the employee can be tracked by the manager. Also the time period they spend on that duty leave is added to the employee's working hours. Employees can apply leaves using both mobile and web applications. Upon the decision by the manager, system is implemented in a way that the manager can accept or reject the leave request made by the employee. Then the response is send to the relevant employee as a notification. The notifications on the reduction of the working hours by the employees to alert them to apply leave was also implemented through both the web app and the mobile app. The employees are facilitated with the ability to view their attendance and leave details in case that if they need to check in-advance to apply for a leave through both web ad mobile app. Scheduling the daily task of the employees also supported by both the apps. The system is developed in a manner that it satisfies the main requirement of the customer, which is the generation of the summary reports through the attendance and leave data, to analyze the patterns. This is implemented in the web app only.

\section{EVALUATION}

To identify the perception of the web application and the android application a feedback form was given among 44 users. Feedbacks were taken in different perspectives.

TABLE 2.

Table for user feedback analysis

\begin{tabular}{|c|c|c|c|c|c|c|c|c|}
\hline \multirow{2}{*}{ Evaluation Aspects } & \multicolumn{5}{|c|}{ Rating } & & & \\
\hline & Very & Good & Satisfactory P & Poor & Very & & & \\
\hline & 5 & & 3 & 2 & & Total score & $\begin{array}{l}\begin{array}{l}\text { No. of } \\
\text { responses }\end{array} \\
\end{array}$ & Rating \\
\hline System availability of the application & 8 & 25 & 10 & & 0 & 172 & 44 & 3.91 \\
\hline Performance of the application & 13 & 17 & 12 & & 0 & 171 & 43 & 3.98 \\
\hline User experience of the system & s & 1. & 12 & 4 & 0 & 165 & 44 & 3.75 \\
\hline Effectiveness of the application & 10 & 2 & 11 & & 0 & 171 & 44 & 3.89 \\
\hline $\begin{array}{l}\text { Degree of achieving the objectives by the } \\
\text { system(different aspects, responsiveness, usability, } \\
\text { value addition, robustness, etc) }\end{array}$ & 10 & 18 & 15 & & 0 & 169 & 44 & 3.84 \\
\hline Adaptability of the application & s & 2 & 13 & & 0 & 170 & 44 & 3.86 \\
\hline & 58 & 12 & 73 & 10 & 0 & 1018 & 263 & 3.87 \\
\hline
\end{tabular}


Proc. of the Eighth Intl. Conf. on Advances in Computing, Electronics and Communication - ACEC 2019

Copyright $\odot$ Institute of Research Engineers and Doctors. All rights reserved. ISBN: 978-1-63248-165-8 DOI : 10.15224/978-1-63248-165-8-01

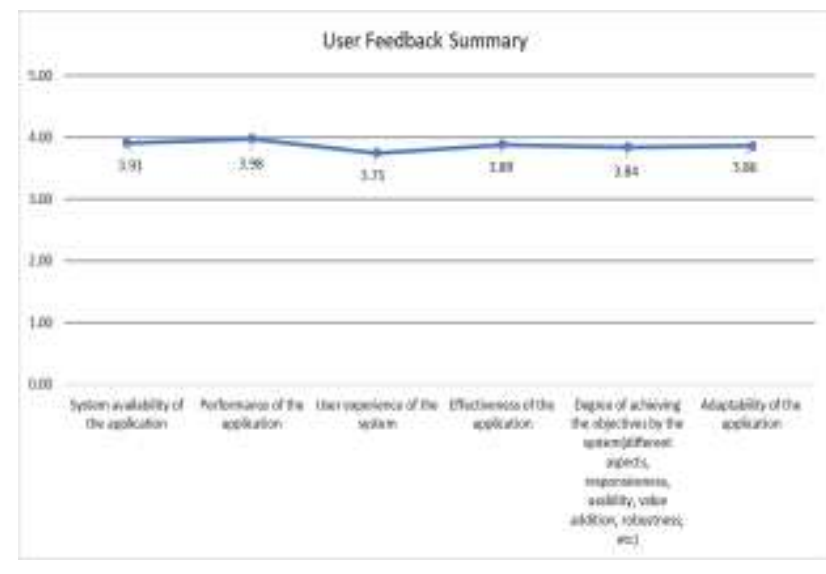

Fig. 2 Summary of feedbacks

The evaluation aspects that we have taken into consideration were System availability of the application, Performance of the application, User experience of the system, Effectiveness of the system, Degree of achievement of the objectives by the system such as different aspects, responsiveness, usability, value addition, robustness etc. and Adaptability of the application.

The statistics revealed positive attitudes of the users with the average rating of almost 4 for all six evaluation aspects. The system availability and the performance of the system were the most important aspects that we have focused on. Other than the above two aspects user experience, adaptability of the system for changes, effectiveness and the degree of the achievement of objectives were also evaluated into order to get an overall feedback about the research that we have carried out.

System availability of the application obtained 3.98 rating while the performance of the application obtained 3.98 rating. System supports for applying online leaves viewing their attendance details and leave details. And 3.86 rating was received for the adaptability of changes. Since the location tracking is a unique feature that can be seen in the system effectiveness of the system obtained a 3.89 rating. So through the feedback of average value of 4 , the research can be said to have a positive outcome.

\section{A Limitations}

The limitation that can be seen in this system is unable to monitor the leaving of more than one person using a single finger print. For further explanation the door will get open with the fingerprint of one person, but at the mean time some other may enter with that access as well. This is an issue that we have identified in this system regarding the reliability of the data contain in the system on the attendance.

\section{B Further works}

There are some further implementation criteria's we have identified. One of those is addition of a methodology to directly update the database of attendance management system from the fingerprint scanners. And also we have developed only an android mobile app to enhance the mobile accessibility, this stage can be further improved through the allocations of mobile accessibility for IOS and windows users as well. These implementations would add more value to this system, can make the system more useful.

\section{CONCLUSION}

Attendance management concept plays a significant role in information technology industry. Although there are many web applications to manage the attendance of employees, there is no proper way to inform each and every employee about their weekly attendance and to calculate the duty leaves of employees. This issue has been addressed by this system. Other than the above mentioned issue this system provides online leave applying capability, handling duty leaves viewing attendance and leave details, and generating reports. Finally this integrated system can be viewed as an effective system for attendance management in a company.

\section{ACKNOWLEDGMENT}

On behalf of the team Technocoders we would like to pay our acknowledgment to all the once who supported us for the successful completion of the second year research Attendance Management System that we implemented on the purpose of our client eBuilder. We would like to make this a chance to thank all the professors, lecturers, academic staff and the seniors of our faulty who helped us in this research. Nextly, our special thank goes to our client eBuilder who help us at the time of difficulties that comes across us during the development of the system. The completion of this research will not be a success without all of your support and dedication. 
Proc. of the Eighth Intl. Conf. on Advances in Computing, Electronics and Communication - ACEC 2019

Copyright $\odot$ Institute of Research Engineers and Doctors. All rights reserved. ISBN: 978-1-63248-165-8 DOI : 10.15224/978-1-63248-165-8-01

\section{REFERENCES}

[1] Dr. Muhammad Zubair Asghar Institute Of Computing And Information Technology Gomal university -Web based attendance management system

[2] Frayne A.Colette, Latham P.Gary - Application of Social Training Theory to Employer Self-Management of Attendance, Journal of Applied Psychology-August 1987

[3]http://www.opportune.in/opt-hrms-software/time-and-attendancemanagement-system/

[4] https://en.wikipedia.org/wiki/ASP.NET

[5] https://en.wikipedia.org/wiki/Microsoft_SQL_Server

[6] Latham P.Gary, Frayne A.Colette -Self-Management Training for increasing Job Attendance: A follow - up and a replication, Journal of Applied Psychology-June 1989
[7] M.D. Shakil, Rabindra Nath Nandi- Attendance management system for industrial worker using fingerprint scanner

[8] O.Shoewu, O.A.Idowu - Development of Attendance Management System using Biometrics

[9] Seema Rao, Prof.K.J.Satoa - An Attendance Monitoring System using Biometrics Authentication, International Journal of Advanced Research in Computer Science and Software Engineering- April 2013

[10] Shakil M.D., Rabindra Nath Nandi - Attendance Management System for Industrial Worker using Fingerprint Scanner, Double Blind Peer Reviewed International Research Journal-2013

[11] Tabassam Nawaz - Development of Academic Attendance monitoring system using Fingerprint Identification

[12] Tolulope Awode, Oluwagbemiga Showu, Oluwabukola Mayowa Ishola, Segun O. Olatinwa - Development of a Networked Thumb Print base Staff Attendance Management System 